\title{
Phytic Acid Protects against 6-Hydroxydopamine-Induced Dopaminergic Neuron Apoptosis in Normal and Iron Excess Conditions in a Cell Culture Model
}

\author{
Qi Xu, ${ }^{1}$ Anumantha G. Kanthasamy, ${ }^{2}$ and Manju B. Reddy ${ }^{3}$ \\ ${ }^{1}$ Foreign Language Center, Shanghai University of Traditional Chinese Medicine, Shanghai 201203, China \\ ${ }^{2}$ Department of Biomedical Sciences, Iowa State University, Ames, IA 50011, USA \\ ${ }^{3}$ Department of Food Science and Human Nutrition, Iowa State University, Ames, IA 50011, USA
}

Correspondence should be addressed to Manju B. Reddy, mbreddy@iastate.edu

Received 29 July 2010; Accepted 13 January 2011

Academic Editor: Carlo Colosimo

Copyright (C) 2011 Qi Xu et al. This is an open access article distributed under the Creative Commons Attribution License, which permits unrestricted use, distribution, and reproduction in any medium, provided the original work is properly cited.

\begin{abstract}
Iron may play an important role in Parkinson's disease (PD) since it can induce oxidative stress-dependent neurodegeneration. The objective of this study was to determine whether the iron chelator, phytic acid (IP6) can protect against 6-hydroxydopamine(6-OHDA-) induced apoptosis in immortalized rat mesencephalic dopaminergic cells under normal and iron-excess conditions. Caspase-3 activity was increased about 6-fold after 6-OHDA treatment (compared to control; $P<.001$ ) and $30 \mu \mathrm{mol} / \mathrm{L}$ IP6 pretreatment decreased it by $38 \%(P<.05)$. Similarly, a $63 \%$ protection $(P<.001)$ against 6 -OHDA induced DNA fragmentation was observed with IP6 pretreatment. Under iron-excess condition, a 6-fold increase in caspase-3 activity $(P<.001)$ and a $42 \%$ increase in DNA fragmentation $(P<.05)$ with 6-OHDA treatment were decreased by $41 \%(P<.01)$ and $27 \%(P<.05)$, respectively, with $30 \mu \mathrm{mol} / \mathrm{L}$ IP6. Together, our data suggest that IP6 protects against 6-OHDA-induced cell apoptosis in both normal and iron-excess conditions, and IP6 may offer neuroprotection in PD.
\end{abstract}

\section{Introduction}

Parkinson's disease (PD) is a progressive neurodegenerative disease affecting more than $1 \%$ of the US population over 50 years of age and causing an approximate economic loss of $\$ 25$ billion annually [1]. The loss of nigral neurons in the substantia nigra results in severe dopamine depletion in the striatum, and clinical signs of PD appear when striatal dopamine is reduced by $80 \%$ [2].

Oxidative stress has been implicated in the neurological degeneration associated with PD since oxidative stress can cause damage to the proteins, DNA, and lipids and consequently induce apoptosis [3]. Oxidative stress results from increased production of reactive free radicals such as reactive oxygen species (ROS). Brain tissue is highly susceptible to oxidative stress because of its high polyunsaturated fatty acids content. In addition, brain may be highly susceptible to oxidative damage because of low antioxidants and high oxidative stress environment. Higher levels of protein carbonyls, lipid hydroperoxides, and DNA damage, such as 8-hydroxyguanine, in PD brains compared to normal brains supported the hypothesis [3]. In addition, the antioxidant enzymes, superoxide dismutase, and catalase concentrations were reported to be 7 - and 140-fold lower in the brain than in the liver $[4,5]$.

Role of iron in the pathogenesis of PD has gained attention recently because of its involvement in oxidative stress [6]. Iron is an essential nutrient for all living organisms since iron plays an important role in many biological processes [7]. However, it can also be involved in producing hydroxyl radicals. In the brain, excess iron can interact with neuromelanin to increase oxidative stress and induce neurodegeneration [8]. Iron concentrations in the substantia nigra of $\mathrm{PD}$ patients are higher than in age matched healthy controls. Alteration in iron metabolism, such as distribution of iron with transport and storage proteins, has also been reported in PD $[9,10]$. Although it is still not clear whether iron accumulation is a cause or an effect, the use of 
antioxidant iron chelators as therapeutic adjuncts in the treatment of PD provides hope to slow down the progression of the neurodegeneration.

Phytic acid (IP6, myoinositol hexakisphosphate) is a food component, that is, considered as an antinutrient due to its ability to chelate divalent minerals and prevent their absorption but also considered as an antioxidant due to the same property in inhibiting hydroxyl radicals formation $[11,12]$. Phytic acid may also influence oxidative stress by altering cell signaling pathways or influencing the activity and expression of antioxidant enzymes and also may be beneficial in preventing many types of cancers $[13,14]$. However, its role in neurodegenerative disease is not well studied. The current study was designed to determine IP6's neuroprotective effect on 6-hydroxydopamine- (6-OHDA-) induced PD in a cell culture model.

\section{Materials and Methods}

2.1. Chemicals. The immortalized rat mesencephalic dopaminergic neuronal cell line (1RB3AN27, generally referred to as N27) was a kind gift from Dr. Kedar N. Prasad, University of Colorado Health Sciences Center (Denver, CO). Ferrous sulfate, 6-OHDA, IP6, and nitrilotriacetic acid (NTA) were purchased from Sigma-Aldrich (St. Louis, MO). Substrate for caspase-3, Acetyl-Asp-Glu-Val-Asp-AFC (AcDEVD-AFC), was obtained from MP Biomedicals (Solon, $\mathrm{OH}$ ). Cell Death Detection (enzyme-linked immunosorbent assay) Plus kit and Hoechst 33342 were purchased from Roche Diagnostics (Indianapolis, IN) and Molecular Probes (Eugene, OR), respectively. RPMI-1640 medium, fetal bovine serum, L-glutamine, penicillin, and streptomycin were obtained from Invitrogen (Carlsbad, CA). All the solutions were prepared fresh prior to each assay.

2.2. Cell Culture. Cells were grown in RPMI-1640 medium containing $10 \%$ fetal bovine serum, $2 \mathrm{mmol} / \mathrm{L} \mathrm{L}$-glutamine, 50 units penicillin, and $50 \mu \mathrm{g} / \mathrm{mL}$ streptomycin and maintained at $37^{\circ} \mathrm{C}$ in a humidified atmosphere containing $5 \%$ $\mathrm{CO}_{2}$ as described in previous studies $[15,16]$. Cells grown for $24 \mathrm{~h}$ were used for the following experiments.

2.3. Treatment. Based on the cytotoxic effects of phytic acid and iron in the previous study [17], 30 and $100 \mu \mathrm{mol} / \mathrm{L}$ IP6 and $50 \mu \mathrm{mol} / \mathrm{L}$ iron were selected in the experiments. For determining the protective effect of IP6 in normal iron conditions, cells were pretreated with $30 \mu \mathrm{mol} / \mathrm{L}$ of IP6 for 24 -h, followed by a $100 \mu \mathrm{mol} / \mathrm{L} 6-\mathrm{OHDA}$ treatment for $6 \mathrm{~h}$. Iron-excess condition in the cells was induced by treating the cells with $50 \mu \mathrm{mol} / \mathrm{L}$ iron for $24 \mathrm{~h}$ prior to IP6 (30 or $100 \mu \mathrm{mol} / \mathrm{L}$ ) followed by 6 -OHDA treatment for another 6 h. Treatments without iron, IP6, and 6-OHDA served as controls for all the experiments.

2.4. Caspase-3 Activity. Caspase-3 was measured as described previously [18]. After each treatment, the cell pellet after centrifugation was lysed with Tris buffer $(50 \mathrm{~mol} / \mathrm{L}$ Tris$\mathrm{HCL}, 1 \mathrm{mmol} / \mathrm{L}$ EDTA, and $10 \mathrm{mmol} / \mathrm{L}$ EGTA at $\mathrm{pH}=7.4$ ) containing $10 \mu \mathrm{mol} / \mathrm{L}$ digitonin for $20 \mathrm{~min}$ at $37^{\circ} \mathrm{C}$. Lysates were subjected to a quick centrifugation at $20,000 \times \mathrm{g}$ and cell-free supernatant was collected. After incubating with a specific fluorogenic caspase- 3 substrate (Ac-DEVDAFC, $50 \mu \mathrm{mol} / \mathrm{L}$ ) for $1 \mathrm{~h}$ at $37^{\circ} \mathrm{C}$, the caspase-3 activity was measured by florescence using microplate reader (Model:Gemini XS, Molecular Devices) with excitation at $380 \mathrm{~nm}$ and emission at $469 \mathrm{~nm}$. The caspase-3 activity was expressed as fluorescent units (FUs)/mg protein.

2.5. DNA Fragmentation. DNA fragmentation assays were performed using Cell Death Detection ELISA Plus Kit as described previously [15]. After each treatment, cell pellet was incubated with $40 \mu \mathrm{L}$ of lysis buffer for $20 \mathrm{~min}$ at room temperature. The lysates were then centrifuged and $80 \mu \mathrm{L}$ immunoreagent containing anti-histone-biotin and antiDNA-POD were added to $20 \mu \mathrm{L}$ supernatant in streptavidincoated 96 well microtiter plates. The plates were incubated at room temperature for $2 \mathrm{~h}$ and then washed twice with incubation buffer. After adding $100 \mu \mathrm{L}$ of 2,2'-azino-di- [3ethylbenzthiazoline sulfonate] (ABTS) solution to each well, the absorbance was measured at $490 \mathrm{~nm}$ and $405 \mathrm{~nm}$ using a microplate reader. DNA fragmentation was measured by the difference in absorbance at 405 and $490 \mathrm{~nm}$ and expressed as absorbance units (AUs)/mg protein.

2.6. Hoechst Nuclear Staining. A fluorescent DNA-binding dye, Hoechst 33342, was used to measure apoptosis. Cells were grown on poly-l-lysine-coated cover slips for $24 \mathrm{~h}$ and then subjected to treatments followed by fixing with $4 \%$ paraformaldehyde. The nuclei were stained with Hoechst $33342(10 \mu \mathrm{g} / \mathrm{mL})$ dye for $5 \mathrm{~min}$ in the dark. Cells were examined under fluorescence microscope (Nikon, Tokyo, Japan) for image analysis. Nuclei of apoptotic cells were identified as heterogeneous patchy inclusions due to chromatin condensation, while nuclei of the nonapoptotic cells were identified as diffused and homogenous manner after staining [16].

2.7. Statistics. Data were analyzed with Prism 4.0 software (Graph Software, San Diego, CA). Caspase-3 activity and DNA fragmentation were expressed as percentage of the respective controls. The differences among the treatments were compared with ANOVA with Tukey's Multiple Comparison test and considered significant at $P \leq .05$.

\section{Results}

3.1. Protection of IP6 against 6-OHDA-Induced Apoptosis. The protective effect of IP6 against 6-OHDA-induced apoptosis was measured with caspase-3 activity (a) and DNA fragmentation (b) and Hoechst nuclear staining (c) as shown in Figure 1. Caspase- 3 activity was about 6 -fold $(P<.001)$ higher with 6-OHDA treatment, but significantly $(P<.05)$ reduced by $38 \%$ with IP6. Similarly, DNA fragmentation increased by 3 -fold $(P<.001)$ with 6-OHDA treatment compared to the control, and IP6 pretreatment completely counteracted the effect $(P<.001)$. The Hoechst nuclear 


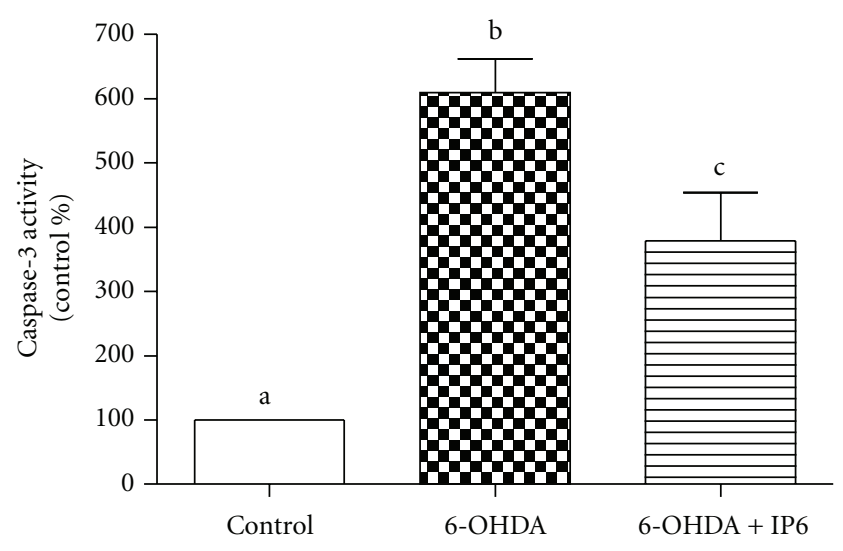

(a)
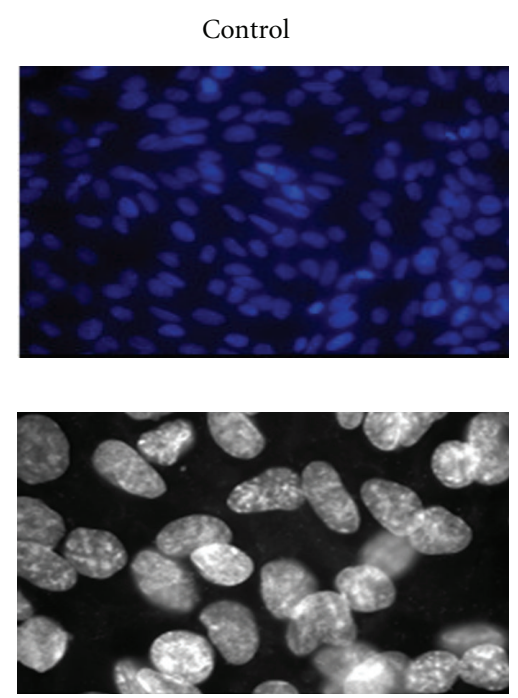

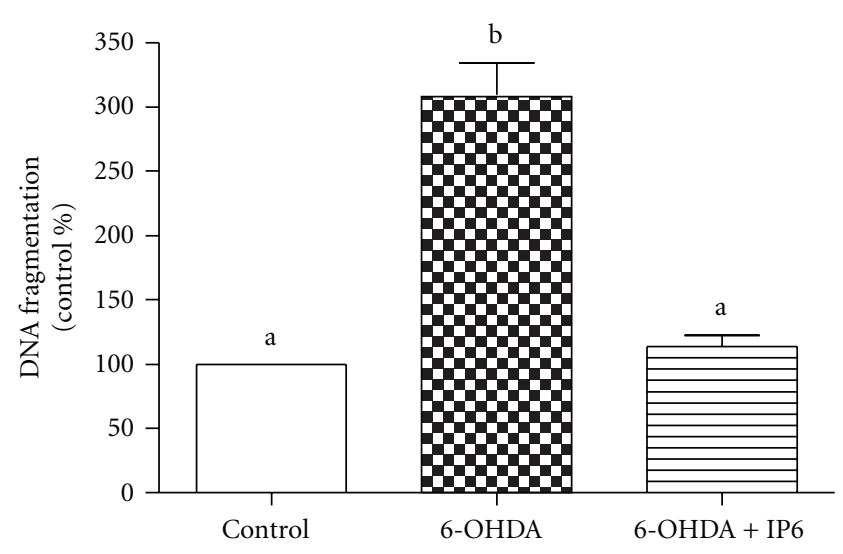

(b)
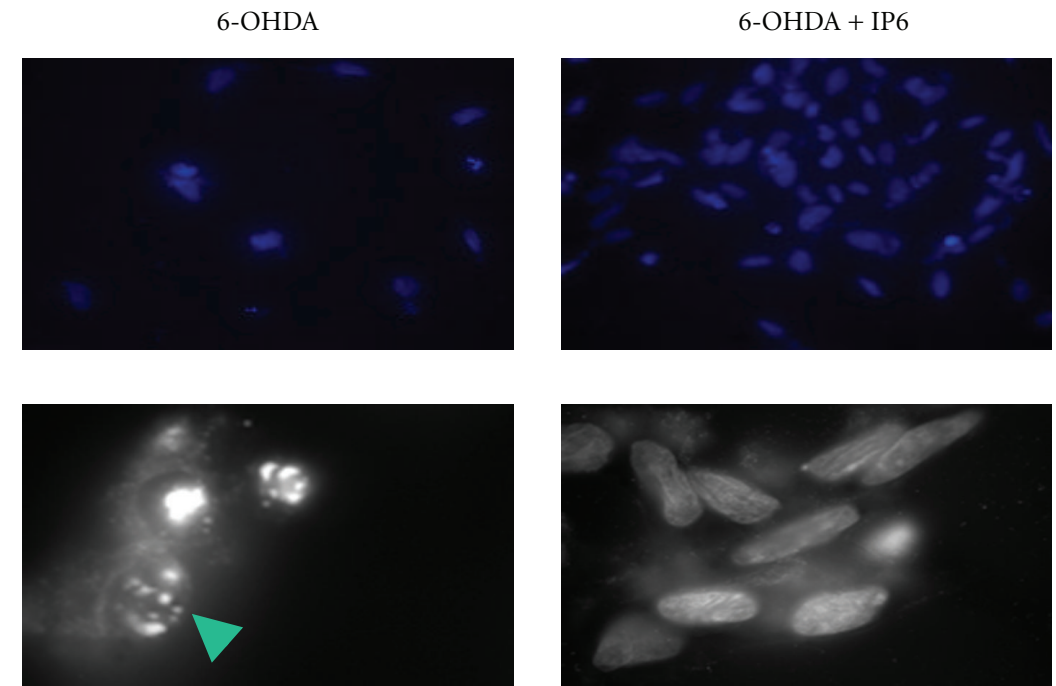

(c)

FIGURE 1: Protection of IP6 $(30 \mu \mathrm{mol} / \mathrm{L})$ against 6-OHDA-induced apoptosis in vitro cell culture model. Cell apoptosis was measured as caspase- 3 activity (FU/mg protein, (a) $n=10$ from two separate experiments) and DNA fragmentation (AU/mg protein, (b) $n=3$ from one experiment) and Hoechst nuclear staining (c). ANOVA with Tukey's Multiple Comparison test was used to detect the differences among the treatments in (a) and (b), and means with different letters were significantly different $(P<.05)$. The top panel in $\mathrm{C}$ represents $20 \mathrm{x}$ magnification and the bottom panel represents $60 \mathrm{x}$ magnification. Apoptotic nucleus is indicated with an arrow.

staining clearly shows cell apoptosis with 6-OHDA and supports the caspase- 3 and DNA fragmentation data on the protective effect of IP6.

\subsection{Protection of IP6 against 6-OHDA-Induced Apoptosis} in Iron-Excess Condition. Protective effect IP6 against 6OHDA-induced apoptosis in iron-excess condition was shown in Figure 2. We also choose to test with higher concentration of IP6 $(100 \mu \mathrm{mol} / \mathrm{L})$ in the caspase- 3 experiment since we did not see a complete protection with $30 \mu \mathrm{mol} / \mathrm{L}$. Caspase-3 activity was not affected by iron alone treatment in our previous study [17]; however, it was increased about 6-fold $(P<.001)$ with 6-OHDA and iron (a). A 41\% $(P<.01)$ protection was found with $30 \mu \mathrm{mol} / \mathrm{L}$ IP6, but no additional protection was shown at the higher concentration of $100 \mu \mathrm{mol} / \mathrm{L}$. DNA fragmentation (b) was increased by $42 \%$
$(P<.05)$ with $6-\mathrm{OHDA}$ and IP6 at $30 \mu \mathrm{mol} / \mathrm{L}$ counteracted the effect $(P<.05)$. Again, Hoechst nuclear staining supports the protection of IP6 against 6-OHDA-induced apoptosis in iron-excess conditions.

\section{Discussion}

Oxidative stress, which may be due to excess iron accumulation, mitochondrial dysfunction, and decreased antioxidant status [19], is attributed to the pathogenesis of nigral cell death in PD. Nonferritin-bound iron may be involved in oxidation of dopamine to release hydrogen peroxide and highly toxic hydroxyl radicals $[20,21]$. Iron may also increase intracellular alpha-synuclein, the abnormal protein aggregation associated with the pathophysiology of PD [22, 23]. Since IP6 is a natural antioxidant with iron chelating ability, 


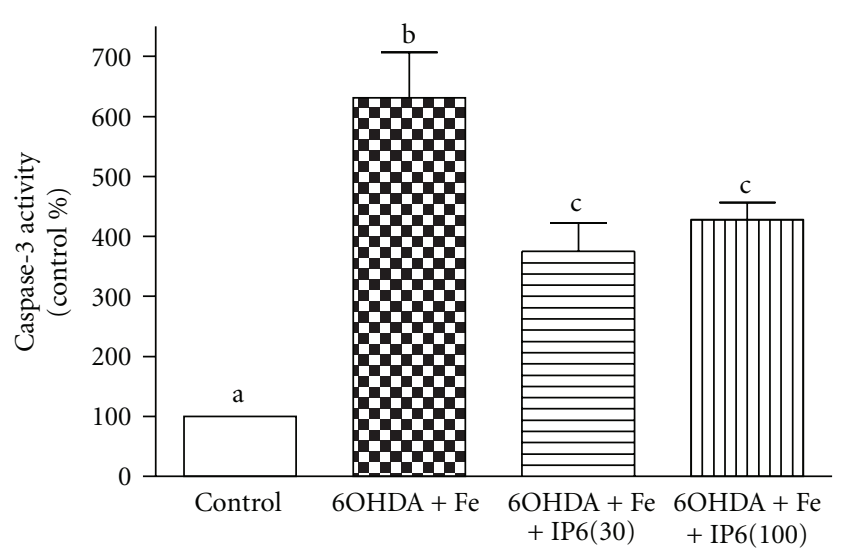

(a)
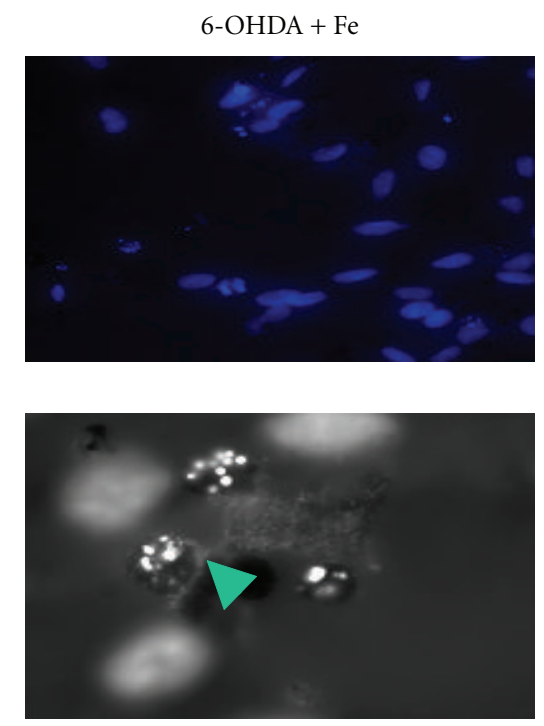

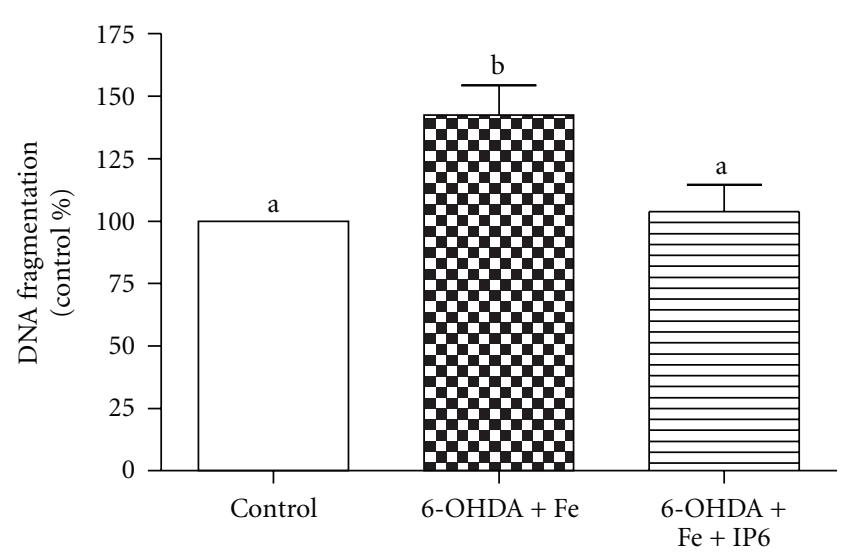

(b)
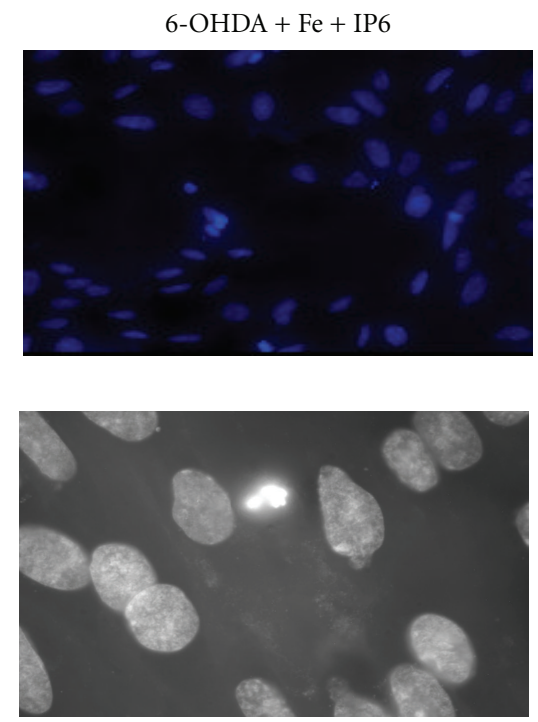

(c)

Figure 2: Protection of IP6 against 6-OHDA-induced apoptosis in the iron-excess condition in vitro cell culture model. Cell apoptosis was measured as caspase- 3 activity (FU/mg protein, (a) $n=4-5$ from one experiment) with 30 and $100 \mu$ mol/L IP6. DNA fragmentation (AU/mg protein, (b) $n=3-4$ from one experiment) and Hoechst nuclear staining (c) were tested with only $30 \mu \mathrm{mol} / \mathrm{L}$ of IP6. ANOVA with Tukey's Multiple Comparison test was used to detect the differences among the treatments in (a) and (b), and means with different letters were significantly different $(P<.05)$. The top panel in $C$ represents $20 \mathrm{x}$ magnification and the bottom panel represents $60 \mathrm{x}$ magnification. Apoptotic nucleus is indicated with an arrow.

this study was aimed at determining the protective effect of IP6 on PD. Although the data is very limited, one study reported the protection of IP6 against 1-methyl-4-phenyl1,2,3,6-tetrahydropyridine- (MPTP-) induced hydroxyl radical generation by chelating iron in rat striatum [24].

The neurotoxin, 6-OHDA, has been shown to cause neural degeneration via hydroxyl radical in the presence of iron [25] as well as inducing apoptosis via caspase3-dependent activation [26]. Exposure of $100 \mu \mathrm{mol} / \mathrm{L} 6-$ OHDA for $24 \mathrm{~h}$ increased caspase- 3 activity by 2.5 -fold and DNA fragmentation by $93 \%$ in one cell culture study [27]. Similarly, we showed a 6-fold increase of caspase-3 activity and 3-fold increase of DNA fragmentation with the same dose but shorter exposure $(6 \mathrm{~h})$ in our study. Adding iron did not further increase the toxicity induced by 6-OHDA.
The effectiveness of IP6 in deceasing caspase-3 activity was not improved with higher dose. We did not test higher concentration of IP6 in the DNA fragmentation experiment because $30 \mu \mathrm{mol} / \mathrm{L}$ IP6 completely counteracted the increase of DNA fragmentation induced by 6-OHDA and iron.

Since 6-OHDA may release iron from ferritin and promote lipid peroxidation [28], studies are aimed at using iron chelators in attenuating 6-OHDA-induced neurotoxicity. Desferrioxamine (DFO) and catechin, the major polyphenol in green tea, were used to study the protective effects against 6-OHDA-induced toxicity in both in vivo and in vitro studies $[29,30]$. Prior injection of DFO to rats resulted in a $60 \%$ protection in striatal dopamine content and a normalization of dopamine release [30]. In another cell culture study, catechin at the concentrations of 3.4 and 
$34 \mu \mathrm{mol} / \mathrm{L}$ significantly protected against 6 -OHDA-induced oxidative damage and cell death [29].

Although DFO is a well-known iron chelator, it may cause some side effects such as seizures, wheezing, blurred vision, and irregular heart beats in patients since it must be administered at a high dosage to overcome its low ability to cross the blood brain barrier $[9,31]$. Our results suggest that IP6 might be as effective but safer than DFO because no toxicity was found with long-term administration [14]. Although neuronal toxicity was observed when $10 \mathrm{nmol} / \mathrm{L}$ or $50 \mathrm{nmol} / \mathrm{L}$ IP6 was directly injected into the hippocampus [32], the cytotoxic effect may be due to the high dose of IP6. However, the dose used in our study is within the normal physiological range since we have shown that there was no cytotoxicity induced by IP6 up to $600 \mu \mathrm{mol} / \mathrm{L}$ in our previous study [17], and humans consume large amounts (2-3g) of this compound in their daily diet.

Showing neuroprotection of IP6 in our culture model raises concern about its ability to cross blood brain barrier. It has been demonstrated that IP6 is well absorbed in rodents based on its distribution to various organs including brain after $1 \mathrm{~h}$ of administration [33]. Although the absorption of IP6 in humans is not well known, a recent study showed a $28 \%$ absorption in ileostomy patients [34]. In addition, 10 -fold higher concentration of IP6 in brain compared to other tissues after feeding rats with $10 \mathrm{~g}$ phytic acid in AIN76A-purified diet [35] indicates that dietary IP6 might enter the brain by crossing the blood brain barrier. There is no evidence of IP6 metabolism in human brain, and methods are available [36] to make possible candidates to cross the blood brain barrier.

\section{Conclusion}

In conclusion, IP6 prevented against 6-OHDA-induced apoptosis in our cell culture model in both normal and iron-excess conditions. Since the dose of IP6 required to reach target sites in the brain and to enter the dopaminergic neurons remains to be established, future study is warranted to determine the effect of IP6 in an animal model of PD.

\section{Acknowledgment}

Supported by the Center for Designing Foods to Improve Nutrition, Iowa State University, Ames, IA

\section{References}

[1] R. T. Scheife, G. T. Schumock, A. Burstein, M. D. Gottwald, and M. S. Luer, "Impact of Parkinson's disease and its pharmacologic treatment on quality of life and economic outcomes," American Journal of Health-System Pharmacy, vol. 57, no. 10, pp. 953-962, 2000.

[2] R. Betarbet, T. B. Sherer, and J. Timothy Greenamyre, "Animal models of Parkinson's disease," BioEssays, vol. 24, no. 4, pp. 308-318, 2002.

[3] P. Jenner, . Hunot, . Olanow et al., "Oxidative stress in Parkinson's disease," Annals of Neurology, vol. 53, no. 3, pp. S26-S38, 2003.
[4] M. B. Reddy and L. Clark, "Iron, oxidative stress, and disease risk," Nutrition Reviews, vol. 62, no. 3, pp. 120-124, 2004.

[5] R. R. Crichton, S. Wilmet, R. Legssyer, and R. J. Ward, "Molecular and cellular mechanisms of iron homeostasis and toxicity in mammalian cells," Journal of Inorganic Biochemistry, vol. 91, no. 1, pp. 9-18, 2002.

[6] D. Berg et al., "Iron in neurodegenerative disorders," Neurotoxicity Research, vol. 4, no. 7-8, pp. 637-653, 2002.

[7] E. Pollitt and R. L. Leibel, "Iron deficiency and behavior," Journal of Pediatrics, vol. 88, no. 3, pp. 372-381, 1976.

[8] K. L. Double, M. Gerlach, M. B. H. Youdim, and P. Riederer, "Impaired iron homeostasis in Parkinson's disease," Journal of Neural Transmission, Supplement, no. 60, pp. 37-58, 2000.

[9] X. Zhang, W. Xie, S. Qu, T. Pan, X. Wang, and W. Le, "Neuroprotection by iron chelator against proteasome inhibitorinduced nigral degeneration," Biochemical and Biophysical Research Communications, vol. 333, no. 2, pp. 544-549, 2005.

[10] S. Bharath, M. Hsu, D. Kaur, S. Rajagopalan, and J. K. Andersen, "Glutathione, iron and Parkinson's disease," Biochemical Pharmacology, vol. 64, no. 5-6, pp. 1037-1048, 2002.

[11] I. Vucenik and A. M. Shamsuddin, "Protection against cancer by dietary IP and inositol," Nutrition and Cancer, vol. 55, no. 2, pp. 109-125, 2006.

[12] M. B. Reddy, R. F. Hurrell, M. A. Juillerat, and J. D. Cook, "The influence of different protein sources on phytate inhibition of nonheme-iron absorption in humans," American Journal of Clinical Nutrition, vol. 63, no. 2, pp. 203-207, 1996.

[13] A. M. Shamsuddin, I. Vucenik, and K. E. Cole, "IP: a novel anti-cancer agent,” Life Sciences, vol. 61, no. 4, pp. 343-354, 1997.

[14] I. Vucenik, V. J. Tomazic, D. Fabian, and A. M. Shamsuddin, "Antitumor activity of phytic acid (inositol hexaphosphate) in murine transplanted and metastatic fibrosarcoma, a pilot study," Cancer Letters, vol. 65, no. 1, pp. 9-13, 1992.

[15] C. Latchoumycandane, V. Anantharam, M. Kitazawa, Y. Yang, A. Kanthasamy, and A. G. Kanthasamy, "Protein kinase C $\delta$ is a key downstream mediator of manganese-induced apoptosis in dopaminergic neuronal cells," Journal of Pharmacology and Experimental Therapeutics, vol. 313, no. 1, pp. 46-55, 2005.

[16] S. Kaul, A. Kanthasamy, M. Kitazawa, V. Anantharam, and A. G. Kanthasamy, "Caspase-3 dependent proteolytic activation of protein kinase $\mathrm{C} \delta$ mediates and regulates 1-methyl-4phenylpyridinium (MPP+)-induced apoptotic cell death in dopaminergic cells: relevance to oxidative stress in dopaminergic degeneration," European Journal of Neuroscience, vol. 18, no. 6, pp. 1387-1401, 2003.

[17] Q. Xu, A. G. Kanthasamy, and M. B. Reddy, "Neuroprotective effect of the natural iron chelator, phytic acid in a cell culture model of Parkinson's disease," Toxicology, vol. 245, no. 1-2, pp. 101-108, 2008.

[18] Y. Yang, S. Kaul, D. Zhang, V. Anantharam, and A. G. Kanthasamy, "Suppression of caspase-3-dependent proteolytic activation of protein kinase $\mathrm{C} \delta$ by small interfering RNA prevents MPP-induced dopaminergic degeneration," Molecular and Cellular Neuroscience, vol. 25, no. 3, pp. 406-421, 2004.

[19] K. N. Prasad, W. C. Cole, and B. Kumar, "Multiple antioxidants in the prevention and treatment of Parkinson's disease," Journal of the American College of Nutrition, vol. 18, no. 5, pp. 413-423, 1999.

[20] D. J. Pinero and J. R. Connor, "Iron in the brain: an important contributor in normal and diseased states," Neuroscientist, vol. 6, no. 6, pp. 435-453, 2000. 
[21] D. Kaur and J. K. Andersen, "Ironing out Parkinson's disease: is therapeutic treatment with iron chelators a real possibility?" Aging Cell, vol. 1, no. 1, pp. 17-21, 2002.

[22] S. Turnbull, B. J. Tabner, O. M. A. El-Agnaf, S. Moore, Y. Davies, and D. Allsop, " $\alpha$-synuclein implicated in Parkinson's disease catalyses the formation of hydrogen peroxide in vitro," Free Radical Biology and Medicine, vol. 30, no. 10, pp. 11631170, 2001.

[23] T. Hasegawa, M. Matsuzaki, A. Takeda et al., "Accelerated $\alpha$-synuclein aggregation after differentiation of SH-SY5Y neuroblastoma cells," Brain Research, vol. 1013, no. 1, pp. 5159, 2004.

[24] T. Obata, "Phytic acid suppresses 1-methyl-4-phenylpyridinium ion-induced hydroxyl radical generation in rat striatum," Brain Research, vol. 978, no. 1-2, pp. 241-244, 2003.

[25] D. Blum, S. Torch, N. Lambeng et al., "Molecular pathways involved in the neurotoxicity of 6-OHDA, dopamine and MPTP: contribution to the apoptotic theory in Parkinson's disease," Progress in Neurobiology, vol. 65, no. 2, pp. 135-172, 2001.

[26] K. Hanrott, L. Gudmunsen, M. J. O’Neill, and S. Wonnacott, "6-Hydroxydopamine-induced apoptosis is mediated via extracellular auto-oxidation and caspase 3-dependent activation of protein kinase $C \delta$," Journal of Biological Chemistry, vol. 281, no. 9, pp. 5373-5382, 2006.

[27] A. G. Kanthasamy, V. Anantharam, D. Zhang et al., "A novel peptide inhibitor targeted to caspase-3 cleavage site of a proapoptotic kinase protein kinase $\mathrm{C}$ delta $(\mathrm{PKC} \delta$ ) protects against dopaminergic neuronal degeneration in Parkinson's disease models," Free Radical Biology and Medicine, vol. 41, no. 10, pp. 1578-1589, 2006.

[28] H. P. Monteiro and C. C. Winterbourn, "6-Hydroxydopamine releases iron from ferritin and promotes ferritin-dependent lipid peroxidation," Biochemical Pharmacology, vol. 38, no. 23, pp. 4177-4182, 1989.

[29] H. V. Nobre, G. M. A. Cunha, F. D. Maia, R. A. Oliveira, M. O. Moraes, and V. S. N. Rao, "Catechin attenuates 6hydroxydopamine (6-OHDA)-induced cell death in primary cultures of mesencephalic cells," Comparative Biochemistry and Physiology - C Toxicology and Pharmacology, vol. 136, no. 2, pp. 175-180, 2003.

[30] D. Ben-Shachar, G. Eshel, J. P. M. Finberg, and M. B. H. Youdim, "The iron chelator desferrioxamine (Desferal) retards 6-hydroxydopamine-induced degeneration of nigrostriatal dopamine neurons," Journal of Neurochemistry, vol. 56, no. 4, pp. 1441-1444, 1991.

[31] G. M. Cole, "Ironic fate: can a banned drug control metal heavies in neurodegenerative diseases?" Neuron, vol. 37, no. 6, pp. 889-890, 2003.

[32] G. J. Lees and W. Leong, "Neuronal cytotoxicity of inositol hexakisphosphate (phytate) in the rat hippocampus," Brain Research, vol. 741, no. 1-2, pp. 134-141, 1996.

[33] I. Vucenik and A. M. Shamsuddin, "Cancer inhibition by inositol hexaphosphate (IP6) and inositol: from laboratory to clinic," Journal of Nutrition, vol. 133, no. 11, 2003.

[34] V. Agte, M. Jahagirdar, and S. Chiplonkar, "Apparent absorption of eight micronutrients and phytic acid from vegetarian meals in ileostomized human volunteers," Nutrition, vol. 21, no. 6, pp. 678-685, 2005.

[35] F. Grases, B. M. Simonet, R. M. Prieto, and J. G. March, "Phytate levels in diverse rat tissues: influence of dietary phytate," British Journal of Nutrition, vol. 86, no. 2, pp. 225$231,2001$.
[36] G. Liu, P. Men, P. L. R. Harris, R. K. Rolston, G. Perry, and M. A. Smith, "Nanoparticle iron chelators: a new therapeutic approach in Alzheimer disease and other neurologic disorders associated with trace metal imbalance," Neuroscience Letters, vol. 406, no. 3, pp. 189-193, 2006. 


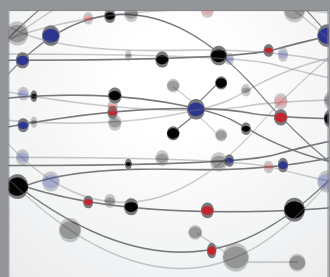

The Scientific World Journal
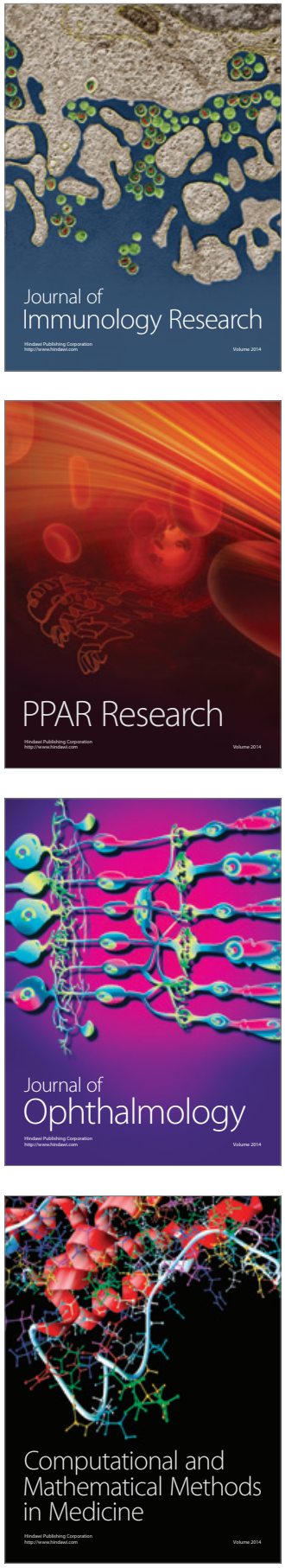

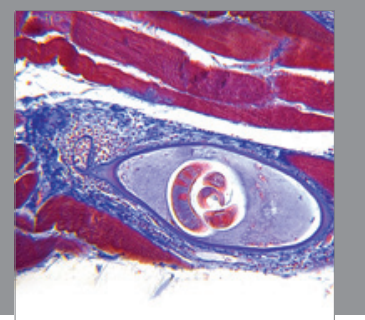

Gastroenterology

Research and Practice
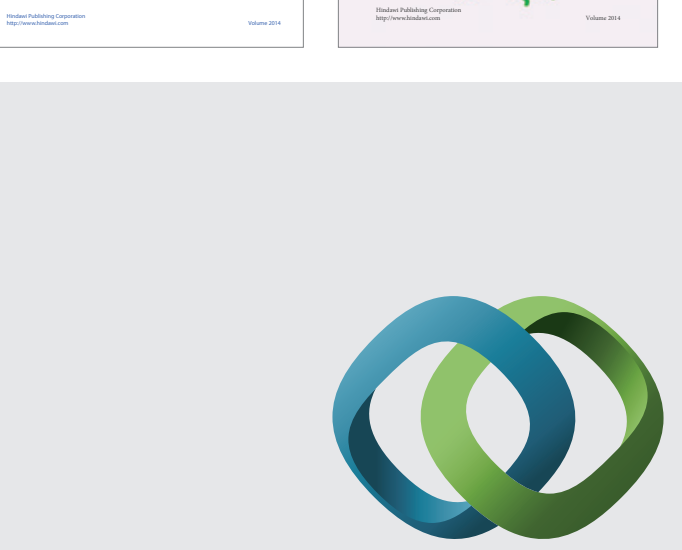

\section{Hindawi}

Submit your manuscripts at

http://www.hindawi.com
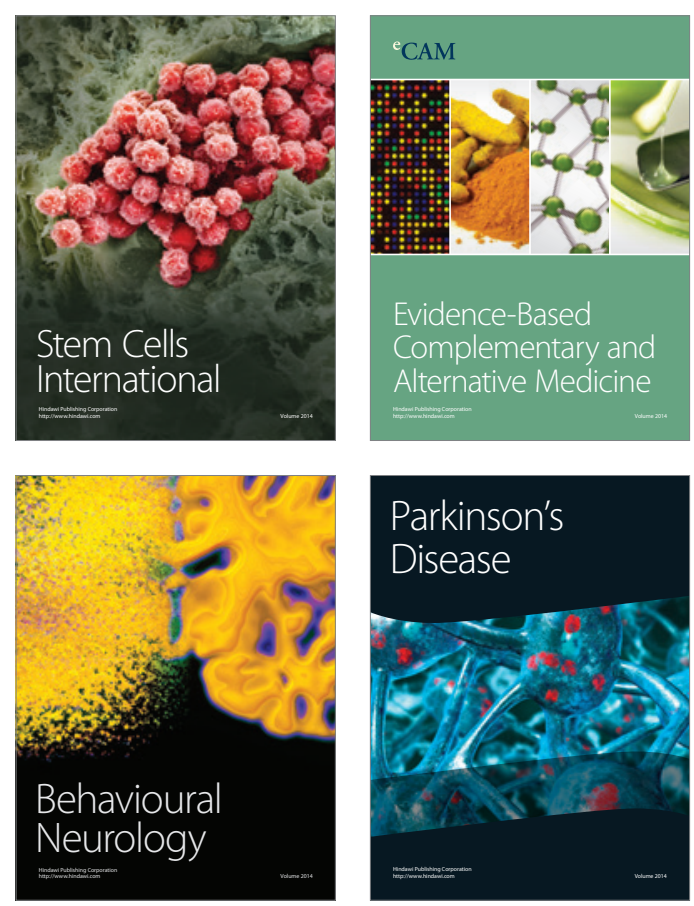

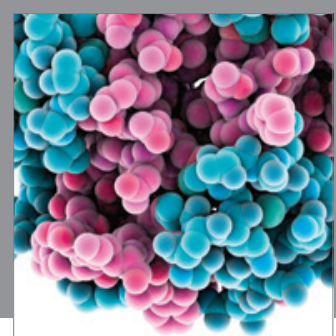

Journal of
Diabetes Research

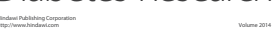

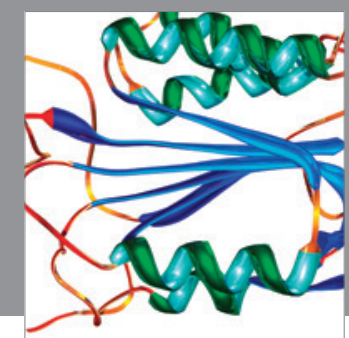

Disease Markers
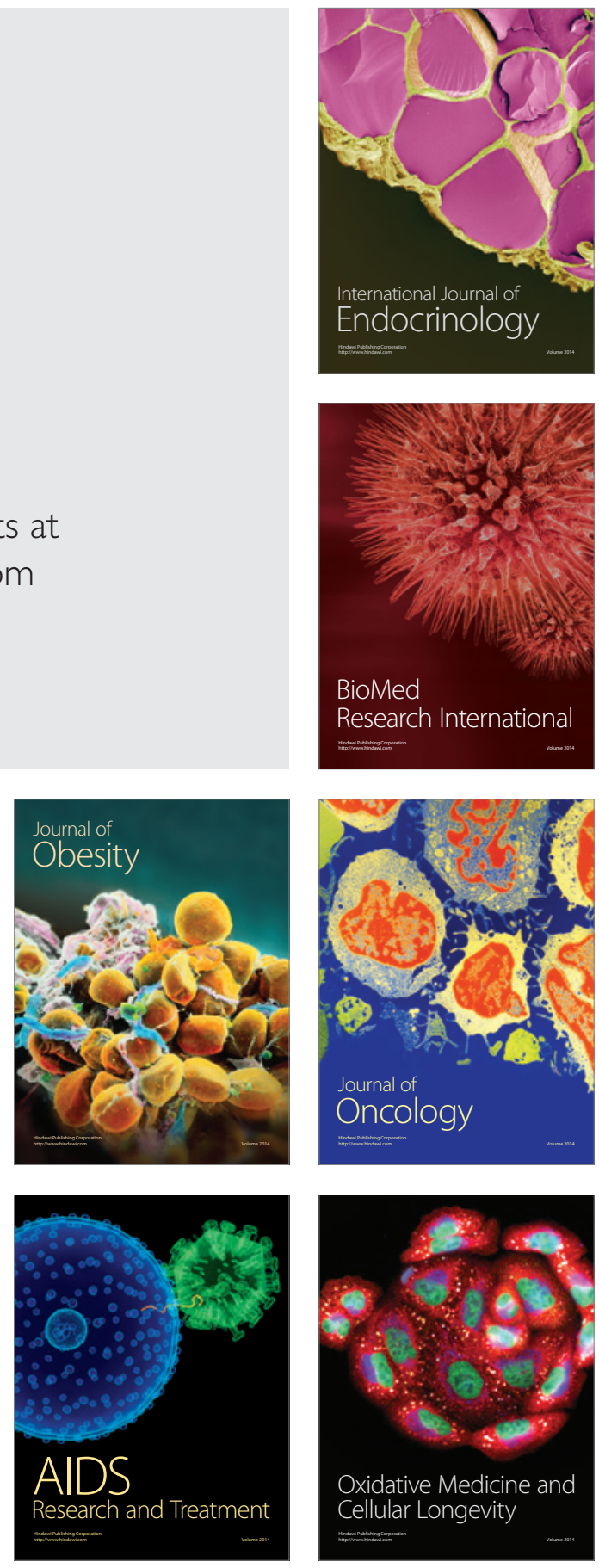